\title{
Discussion Paper No. 16-091 \\ The Power of Active Choice: \\ Field Experimental Evidence on \\ Repeated Contribution Decisions to a \\ Carbon Offsetting Program
}

Martin Kesternich, Daniel Römer, and Florens Flues

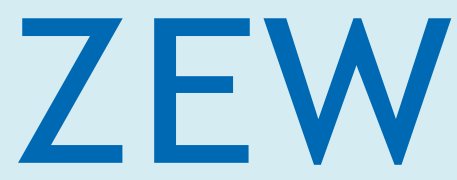

Zentrum für Europäische Wirtschaftsforschung $\mathrm{GmbH}$

Centre for European

Economic Research 
Discussion Paper No. 16-091

\title{
The Power of Active Choice: Field Experimental Evidence on Repeated Contribution Decisions to a Carbon Offsetting Program
}

\author{
Martin Kesternich, Daniel Römer, \\ and Florens Flues
}

Download this ZEW Discussion Paper from our ftp server:

http://ftp.zew.de/pub/zew-docs/dp/dp16091.pdf

Die Discussion Papers dienen einer möglichst schnellen Verbreitung von neueren Forschungsarbeiten des ZEW. Die Beiträge liegen in alleiniger Verantwortung der Autoren und stellen nicht notwendigerweise die Meinung des ZEW dar.

Discussion Papers are intended to make results of ZEW research promptly available to other economists in order to encourage discussion and suggestions for revisions. The authors are solely responsible for the contents which do not necessarily represent the opinion of the ZEW. 


\title{
The Power of Active Choice: Field Experimental Evidence on Repeated Contribution Decisions to a Carbon Offsetting Program
}

\author{
Martin Kesternich ${ }^{*}$, Daniel Römer ${ }^{*}$ and Florens Flues ${ }^{* *}$ \\ * Centre for European Economic Research (ZEW) \\ ** OECD Paris
}

Version: 22 December 2016

\begin{abstract}
:
We study the effect of a subtle change in the choice architecture on offsetting behavior. In a large-scale field experiment, we examine repeated voluntary contributions to a carbon offsetting program during the online purchase of long-distance bus tickets. In the control group, travelers had the option to offset their carbon emissions resulting from their bus trip, but they could also simply ignore the offer. In the treatment group, travelers were forced to actively choose whether to offset their carbon emissions or not. This "active choice" requirement immediately increased participation in the offsetting program by almost 50\%. Investigating returning customers, we find that this treatment remains effective over time. We report evidence that some customers tend to keep avoiding active contribution decisions in subsequent booking decisions.
\end{abstract}

Keywords: voluntary carbon offsets, randomized field experiment, default setting, choice architecture

JEL: H41, C93, D03, L92

Acknowledgement: Financial support by the German Federal Ministry of Education and Research (FKZ 01LA1132C and 01UT1411A) is gratefully acknowledged. Further details can be obtained from http://www.zew.de/staff_mkn and http://www.zew.de/WS372-1. The authors are solely responsible for the contents of their work, which may not necessarily express the opinions of their institutions. We are grateful to Kathrine von Graevenitz, John List, Andreas Lange, Andreas Löschel, Michael Price, Holger Stichnoth, Bodo Sturm and participants at conference and workshop presentations for very valuable comments on earlier versions of this paper.

\section{Correspondence:}

Martin Kesternich (kesternich@zew.de)

Florens Flues (florens.flues@oecd.org)

Daniel Römer (droemer@gmx.de) 


\section{Introduction}

Designing the choice architecture has become a popular tool to influence decision making, both in business and in public policy. As an important example, the effect of default options has been studied in a broad range of settings including organ donation (Johnson and Goldstein 2003), health care services (Bellman et al. 2001), retirement plans (Beshears et al. 2008), green energy campaigns (Pichert and Katsikopoulos 2008), electricity pricing programs (Cappers et al. 2015), or carbon offsetting (Araña and León 2012, Löfgren et al. 2012). Default options are often considered as a leading example for what is now discussed as “nudging” in the behavioral economics literature (Thaler and Sunstein 2008).

A key insight offered by this literature is that individuals tend to remain with the default. Participation rates are higher when participation is set as the default and subjects have the option to "opt out", compared to a setting where non-participation is the default and subjects have the option to “opt in” (e.g., Johnson and Goldstein 2003). One potential explanation for this effect is inattention. Subjects might simply fail to pay attention that they actually had a choice. A related explanation refers to inertia and procrastination, as choosing against the default requires some effort, in particular, when decisions are more complex (e.g., Sunstein and Reisch 2013). Further explanations involve loss aversion as deviating from the status-quo has to provide a higher utility than the default itself (e.g., Dinner et al. 2011) or social conformity as defaults may signal appropriate behavior (e.g., McKenzie et al. 2006).

While defaults may be beneficial to individuals who prefer not to take decisions themselves (Sunstein 2014), there is also a debate on the ethical limitations of their use (Smith et al. 2013). As an example, the European Court of Justice ruled in 2012 that an "opt-out” was illegal in the case of travel insurance that had been automatically added to the online booking of passenger flights (European Court of Justice 2012).

Consequently, the choice architect may want to rely on softer interventions in some contexts. Sunstein and Reisch (2013) suggest that especially in complex or morally loaded decisions, it may be tempting to refuse any decision at all. So why not simply require an explicit decision in such contexts? The "active choice” requirement may reduce the "moral wiggle room" that individuals tend to take advantage of (Dana et al. 2007) and may hence increase voluntary contributions to a public good. In fact, a series of papers has shown that an active choice requirement increases participation in the respective programs compared to an "opt-in” setting 
in one-shot decisions (e.g., Johnson and Goldstein 2003, Pichert and Katsikopoulos 2008, Löfgren et al. 2012).

In related work, Andreoni et al. (forthcoming) nicely demonstrate that a personal ask for donations during a supermarket visit, which might be seen as an alternative way to induce an explicit decision, stimulates higher contributions as opposed to a similar setting without any verbal conversation between the solicitor and the potential donor. At the same time, their findings reveal that some visitors of a supermarket are willing to accept some effort to avoid being asked for donations by choosing another entrance. DellaVigna et al. (2012) report similar behavior in a door-to-door fundraising campaign. They show that subjects try to avoid meeting a solicitor by indicating to be "not at home” when a fundraiser announced his arrival. This observed ask avoidance is considered as a strategic self-control mechanism to limit emotional responses that would otherwise induce own giving (Trachtman et al. 2015).

While the literature seems to confirm that asking individuals to make a choice increases average contributions in the case of public goods, there are still many open questions. In the context of changes in the choice architecture, the literature typically focuses on the immediate short-term effects. In particular, there is a lack of insights regarding the long-term impacts of active choice settings in repeated consumption decisions. Does their effectiveness fade away over time? Does forcing individuals to make a decision also affect subsequent behavior? Moreover, little is known about the different behavioral channels causing the observed actual behavior. Are the reported effects driven by social pressure or by self-image concerns?

In this paper, we study the effect of an active choice requirement on repeated decisions in the framework of a carbon offsetting program. In a large-scale field experiment, we examine voluntary contributions to a carbon offsetting program during the online purchase of a longdistance bus ticket. Offsetting costs are individually calculated and linear in trip distance resulting in an average offsetting price of $€ 0.23$ per booking. In the baseline scenario, subjects have the opportunity to offset their carbon emission, but are also allowed to simply ignore the offer and to continue the booking process without participating in the program. This design represents an "opt-in" setting with non-participation as the default option. In the "active choice” condition, individuals are required to indicate their offsetting decision in order to finalize the purchase of their ticket. Given our randomization strategy, we are able to both investigate consumers' first reaction to the different settings and to study repeated bookings of returning customers being assigned to the same treatment condition. This allows us to present one of the first analyses on the effect of "the ask" in repeated decisions. 
The contribution of the paper is fourfold: First, we can show that the "active choice" requirement increases the share of travelers who offset their carbon emissions by almost $50 \%$ in the first booking decision. To the best of our knowledge, this represents the first evidence on the effects of this framework in a green or impure public good setting where contributions are explicitly tied to harm-related behavior. ${ }^{1}$

Second, we confirm that asking for an explicit decision is effective in fostering public good contributions in a rather anonymous environment of online bookings with a lower degree of social pressure. As the privately requested decision triggers reactions that are similar to public verbal solicitations in the context of charitable giving, our results suggest that self-image concerns are an important driver of the observed effect. Together with recent evidence from Adena and Huck (2016) who investigate the effects of an active choice requirement on charitable giving in an online setting, our study provides one of the first insights into this question.

Third, we add to the scarce literature on the long-term effects of the choice architecture. Investigating the behavior of returning customers within the same treatment conditions, we show that treatment effects of the active choice setting do not fade away over time but lead to persistent behavioral differences in subsequent decisions without substantially affecting the number of recurrences. Our design thereby enables us to shed light on the underlying behavioral channels. Two major long-run effects of the design requiring an active choice can be found. On the one hand, the share of deliberate participation, i.e. customers that choose to offset their corresponding carbon emissions without being forced to decide, is affected and remains substantially higher in repeated decisions compared to the control group. On the other hand, prompting those without a deliberate choice to indicate their decision still effectively increases the share of carbon neutral trips with decreasing efficiency over time. Our observations suggest that a significant share of the passengers constantly attempts to avoid the decision. This finding is consistent with the "avoiding the ask" argument as reported in DellaVigna et al. (2012) and Andreoni et al. (forthcoming).

Finally, we can show the limitations of the long-term effects. The observed persistency seems to be restricted to sufficiently similar choice situations. When introducing matching and

\footnotetext{
${ }^{1}$ In previous field experimental studies on carbon offsetting and default setting, individuals offsetting costs were not related to the underlying trip. Löfgren et al. (2012) study decision behavior of air travelers to a scientific conference in Sweden in 2008. The underlying offsetting costs amount to $€ 10$ for flights from within Europe and $€ 40$ for flights from outside Europe. In a similar study, Araña and León (2012) consider fixed offsetting prices of $€ 10$, €20, $€ 40$ and $€ 60$ investigating the choice behavior for air travelers to scientific conventions and conferences in Gran Canaria from 2009-2011.
} 
rebate subsidies and hence changing the choice environment, behavioral differences between the two groups fade away.

The remainder of the paper is organized as follows. In section 2, we describe the offsetting program and the experimental design. In section 3, we report our results and section 4 concludes.

\section{The field experiment}

\subsection{The offsetting program}

We conducted the field experiment in collaboration with a German long-distance bus operator in October 2013 coinciding with the launch of the carbon offsetting program. The program was introduced without any advertising or pre-announcement and was part of the usual online booking system. It allowed passengers to buy one-way or return tickets for up to four passengers at a time. After having chosen their ticket for the bus travel, participants were asked whether they would like to offset their related carbon emissions (in kilograms of $\mathrm{CO}_{2}$ ) for a given price (in €). Offsets were sold at 8 cents per 100 passenger-kilometer. $^{2}$ In order to minimize information costs, we provided detailed information on the carbon offsetting program upon request for those being interested upon request via click. ${ }^{3}$ In the final cart, passengers obtained a list of items they intended to buy (including their offsetting expenses). They were then asked to add their personal data (no additional information beyond the usual booking process was requested) and to enter their payment details. Collecting post-experiment questionnaire data reveals that the vast majority of the passengers were between 16 and 35 years old. Most of them had an academic background. Men and women were equally represented. ${ }^{4}$

\subsection{Experimental design and procedure}

In the baseline condition, individuals were given the opportunity to offset their carbon emission by choosing “yes". To decline the offer, they could choose "no”. However, they were also allowed to skip the decision and continue booking process by choosing "continue"

\footnotetext{
2 Including both direct carbon emissions from fuel consumption $\left(36 \mathrm{~g} \mathrm{CO}_{2} / \mathrm{km}\right)$ and the life-cycle-assessment for the vehicle based on the GEMIS database (IINAS 2013) individual carbon emissions amounted to $47 \mathrm{~g} \mathrm{CO}_{2}$ per passenger kilometer. The collaborating offsetting provider charged a price of $€ 17.90$ per ton $\mathrm{CO}_{2}$.

3 The bus service provided the information that reductions in greenhouse gas emissions were achieved by supporting an energy efficiency project in the public sector dealing with improved household charcoal stoves in Accra/Ghana. Those reductions were certified as voluntary emissions reductions (VER) according to the Gold Standard, which is often considered the most rigorous international certification benchmark for quality and compliance of voluntary carbon offsetting programs. Using data from an online platform with more than 280 offsetting projects from 97 providers, Conte and Kotchen (2010) show that offsets being labelled as a Gold Standard project allow for a price premium of $30 \%-65 \%$.

${ }^{4}$ We distributed questionnaires both in the busses during randomly determined bus rides after the experiment was finished and online, using the bus operator's email list of customers. In total, we obtained 403 observations.
} 
at the bottom of the page. Consequently, they did not participate in the program. ${ }^{5}$ In the Active Choice (AC) condition, individuals faced the same design but an active choice was explicitly required. If subjects continued without having made their choice, the decision screen was again highlighted with a red frame and a decision request ("please select whether you would like to offset your emissions”) appeared (see translated screenshots in Figure A1). We assigned individuals randomly into the two treatment conditions based on a browser cookie (ID) being saved on the individuals' devices when entering the website for the first time. If individuals interrupted the booking process, returned to the website later and the cookie was not deleted, they would remain within the same treatment. Given this randomization strategy, we are able to investigate repeated bookings of returning customers.

\section{Experimental results}

In total, we observe 11,311 booking decisions with 5,670 observations in the treatment and 5,641 observations in the control group. Summary statistics do not reveal large differences in observables between both settings (see Table 1 for an overview). There is a small but significant difference in the share of females (AC: 53\%, Control: 51\%, p $<0.05$, $\mathrm{Chi}^{2}$-test) and the share of group bookings (AC: 10\%, Control: 9\%, $<<0.10$, Chi ${ }^{2}$-test). In addition, the request for more information on the offsetting program is slightly higher in the AC treatment but generally very low in both groups (AC: $5 \%$, Control: $4 \%, \mathrm{p}<0.01, \mathrm{Chi}^{2}$-test). Within the treatment framework, 9,736 observations result from individuals purchasing a ticket for the first time whereas 1,575 are recorded from customers returning to the website for a subsequent booking. Returning rates are quite similar in both treatments: In the control group, subjects book 1.20 trips on average while in AC, we observe 1.18 trips per individual $(\mathrm{p}<0.10$, $\mathrm{Chi}^{2}$-test). This result differs from the findings of Adena and Huck (2016) who report substantial dropout rates after forcing opera ticket bookers to make a donation decision during the booking process. On average, the travel length amounts to $279 \mathrm{~km}$ per booking resulting in corresponding $\mathrm{CO}_{2}$ emissions of $13.1 \mathrm{~kg}$ and an average offsetting price of $€ 0.23$. We start the discussion of the experimental results by first investigating individuals' immediate response to the different default options. Then, we turn towards subsequent bookings from returning customers.

\footnotetext{
${ }^{5}$ We conducted several separate experiments to study different types of behavioral interventions with the same bus operator. The data for this paper are exclusively taken from the first part of the program. The subsequent treatments on (spillover-) effects of matching grants and price rebates are reported in Kesternich et al. (2016). In this paper, we distinguish between two treatment conditions.
} 
Table 1: Summary statistics by control and treatment group

\begin{tabular}{lccc}
\hline Treatment & Control & $\begin{array}{c}\text { Active } \\
\text { Choice }\end{array}$ & All \\
\hline Total ticket price $(€)$ & 18.53 & 18.81 & 18.67 \\
& $(11.91)$ & $(11.55)$ & $(11.73)$ \\
Offset price (share of total ticket price) & 0.013 & 0.013 & 0.013 \\
& $(0.006)$ & $(0.006)$ & $(0.006)$ \\
$\mathrm{CO}_{2}$ emissions per booking $(\mathrm{kg})$ & 13.2 & 13.2 & 13.1 \\
& $(9.2)$ & $(9.1)$ & $(9.1)$ \\
Travel length per booking $(\mathrm{km})$ & 278.1 & 280.5 & 279.3 \\
& $(195.3)$ & $(192.6)$ & $(193.9)$ \\
Group ticket $(1=$ yes) & 0.09 & $0.10 *$ & 0.09 \\
& $(0.28)$ & $(0.30)$ & $(0.29)$ \\
Return ticket $(1=$ yes) & 0.30 & 0.30 & 0.30 \\
& $(0.46)$ & $(0.46)$ & $(0.46)$ \\
Voucher $(1=$ yes) & 0.01 & 0.02 & 0.01 \\
& $(0.12)$ & $(0.12)$ & $(0.12)$ \\
Info button request $(1=$ yes) & 0.04 & $0.05 * * *$ & 0.04 \\
& $(0.19)$ & $(0.22)$ & $(0.19)$ \\
Female $(1=$ yes) & 0.51 & $0.53^{* *}$ & 0.52 \\
& $(0.50)$ & $(0.50)$ & $(0.50)$ \\
Bookings (\# of bookings by same ID) & 1.20 & $1.18^{*}$ & 1.19 \\
& $(0.60)$ & $(0.53)$ & $(0.57)$ \\
\hline Observations & 5,641 & 5,670 & 11,311 \\
\hline
\end{tabular}

Notes: Means are reported by treatment group, standard deviations in parentheses, asterisks indicate significant differences between Control and Active Choice, in means (t-tests) or proportions (Chi ${ }^{2}$-test), respectively, ${ }^{* * *}{ }^{*}<0.01,{ }^{* *} \mathrm{p}<0.05,{ }^{*} \mathrm{p}<0.10$. A correction for multiple hypotheses testing as suggested by List et al. (2016) reveals that the differences in female and bookings are not significant anymore. The difference in Info button request and group ticket however persists.

\subsection{First booking decision}

While we analyze final participation to show the main effects of the treatment, we will also consider two distinct forms of participation for a deeper analysis: Deliberate participation refers to the deliberate decision to offset without seeing the reminder to make a decision. By construction, individuals in the control treatment can only be deliberate participants. Hence, the two forms coincide in these treatments. In the AC treatment, however, subjects could also choose to participate after they saw the reminder that prompted them to make a decision. If subjects are undecided at first and then opt to compensate their emissions, we will refer to this behavior as prompted participation.

In the first booking decision, a significantly higher share of travelers, i.e. deliberate and prompted participants, offset their carbon emissions in the AC treatment (26.5\%) compared to the control group (17.7\%) (Figure 1, left side panel) ( $\mathrm{p}<0.01$, Chi ${ }^{2}$-test). This observation is in line with findings on organ donations reported in Johnson and Goldstein (2003) based on an online experiment. They report participation rates in an AC treatment (79\%) to be significantly higher than in an opt-in design (42\%). ${ }^{6}$ Also in the context of retirement savings, Carroll et al. (2009) find that savings plan enrollment among employees is 28 percentage

\footnotetext{
${ }^{6}$ They also investigate participation decision in an opt-out frame and find no statistical differences between opt-out (82\%) and AC.
} 
points higher under an active decision regime than under a standard opt-in enrollment regime. Finally, our findings also correspond to the results obtained by Löfgren et al. (2012) on carbon offsetting even though the differences they find between AC (46.8\%) and opt-in (39.3\%) do not differ significantly from zero. The authors explain the missing significance with the characteristics of their subject pool mainly of environmental economists. They conclude that default effects may attenuate with market experience.

We find equal shares of deliberate participation in the AC treatment $(18.0 \%$ of all AC participants) and in the control group (17.7\%) (Figure 1). This finding indicates that the treatment effect is not driven by a selection bias. Of all participants in AC, 48.7\% do not deliberately indicate their decision. About $17.5 \%$ of these individuals (amounting for $8.5 \%$ of the entire AC sample) choose to opt-in when the decision becomes compulsory. This results in an overall increase of participants by roughly $50 \%$ in contrast to the control group (AC: 26.5\%, control: $17.7 \%$ ) in the first booking decision. The remaining $82.5 \%$ of those being reminded decide not to take part in the program when the decision becomes compulsory. Applying a binary logit model indicates that the differences in participation rates between the two treatment conditions are significantly different from zero both in an empirical model with the treatment variable only (Table 2, column 1) and in an expanded model with a set of control variables (column 2). The econometric results predict participation in the offsetting program to increase by about 9 percentage points when the choice architecture requires an active choice.

At first glance, this effect might be mainly driven by inattention. One might suspect that people simply overlook the offsetting possibility in the booking process. In the following, we study decision behavior of returning customers to shed further light on this possibility. 
Figure 1: Participation in repeated bookings (1st to 3rd booking decision)
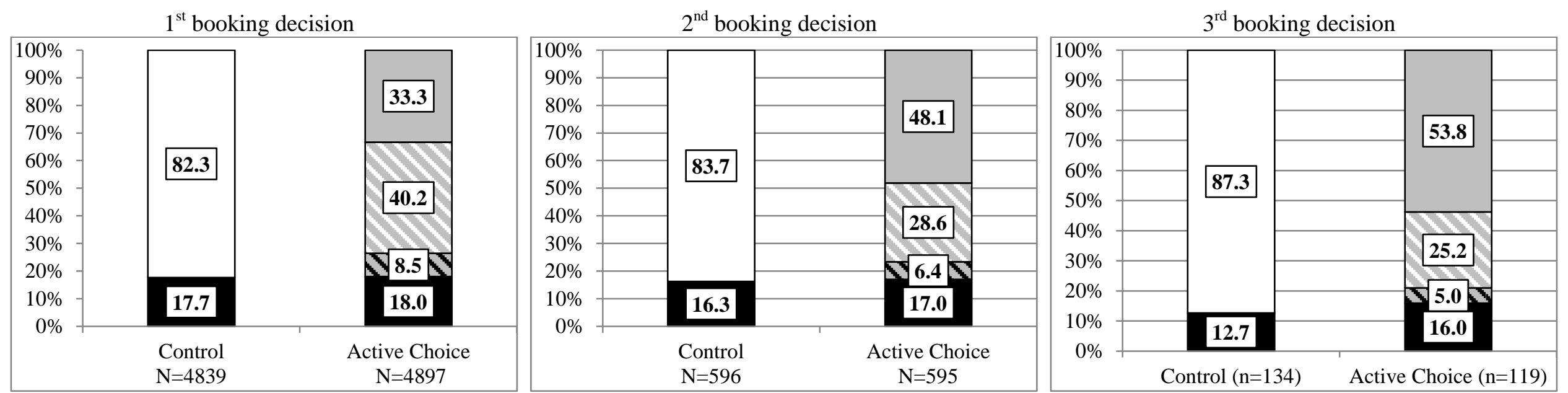

- deliberate participation $\mathbf{\nabla}$ prompted participation $\square$ prompted non-participation $\square$ deliberate non-participation $\square$ non participation

Table 2: Treatment effects, first booking decision

\begin{tabular}{ccc}
\hline & $(1)$ & $(2)$ \\
VARIABLES & Participation & Participation \\
\hline Active choice & $0.088^{* * *}$ & $0.089 * * *$ \\
& $(0.008)$ & $(0.008)$ \\
Controls & No & Yes \\
\hline Observations & 9,736 & 9,736 \\
\hline
\end{tabular}

Notes: Discrete probability effects for treatment indicators are calculated after the ML estimation,

the set of control variables contains: $\mathrm{CO}_{2}$ emissions per booking, offset price, voucher $(1=$ yes $)$,

female $(1=$ yes $)$, standard errors in parentheses, $* * * p<0.01$. 


\subsection{Second booking decision and after}

Due to our randomization procedure, repeated customers were reassigned to the same treatment. We are therefore able to observe the number of repeated bookings of the same passenger, indicating the number of times the individual has been exposed to the treatment. Analyzing subsequent bookings of returning customers allows us to investigate "follow-up" behavior and hence to explore potential long-term effects of the choice structure.

Figure 1 displays the share of passengers that offset their emissions over three subsequent bookings. In the active choice condition, participation is constantly higher in all subsequent booking decisions $\left(2^{\text {nd }}\right.$ decision: $23.4 \%$ vs. $16.3 \%, \mathrm{p}<0.01 ; 3^{\text {rd }}$ decision: $21.0 \%$ vs. $12.7 \%$, $\mathrm{p}<0.10$, Chi ${ }^{2}$-test $)$. Also in relative terms, effect sizes are relatively stable over time $(+50 \%$ in the first decision, $+44 \%$ in the second decision, $+62 \%$ in the third decision). A set of logit regressions confirms the observed treatment effects (Table 3). Absolute effects even seem to increase for subjects taking their $4^{\text {th }}$ decision. However, given the small number of observations in this subgroup, we suspect higher levels of noise for this estimate.

Summarizing, the AC choice architecture does not only increase participation in the first booking decision but also fosters offsetting in repeated booking decisions.

Table 3: Treatment effects, second booking decision and beyond

\begin{tabular}{|c|c|c|c|}
\hline VARIABLES & $\begin{array}{l}\text { (1) } \\
\text { Participation } \\
\text { 2nd decision }\end{array}$ & $\begin{array}{l}\text { (2) } \\
\text { Participation } \\
\text { 3rd decision }\end{array}$ & $\begin{array}{l}\text { (3) } \\
\text { Participation } \\
\text { 4th decision }\end{array}$ \\
\hline Active choice & $\begin{array}{c}0.075^{* * *} \\
(0.023)\end{array}$ & $\begin{array}{c}0.081 * \\
(0.045)\end{array}$ & $\begin{array}{c}0.149 * * \\
(0.073)\end{array}$ \\
\hline Controls & Yes & Yes & Yes \\
\hline Observations & 1,191 & 253 & 84 \\
\hline
\end{tabular}

In a next step, we take a closer look at the development of the two groups over time. There is a clear downward trend in the control group where participations rates drop by $28 \%$ to only $12.7 \%$ in the third booking decision (Figure 1). In the AC condition, we also observe a reduction in overall participation over time, but the effect appears to be weaker. Here, overall offsetting rates drop from $26.5 \%$ to about $21.0 \%$ in the third booking decision.

The weaker decrease in participation in the AC condition also holds for those who deliberately choose to offset. While the share of deliberate participation in AC was equal to the control group in the first booking decision (18.0\% of all participants), it remains higher in all subsequent decisions (17.0\% in AC compared to $16.3 \%$ in control in the second booking, 
$16.0 \%$ in $\mathrm{AC}$ compared to $12.7 \%$ in the third booking). We test for a trend in deliberate participation and find a significant (negative) coefficient only for the case of the control treatment (see Table 4).

Table 4: Deliberate participation, second booking decision and beyond

\begin{tabular}{|c|c|c|c|}
\hline VARIABLES & $\begin{array}{c}(1) \\
\text { Deliberate } \\
\text { Participation } \\
\text { All } \\
\end{array}$ & $\begin{array}{c}\text { (2) } \\
\text { Deliberate } \\
\text { Participation } \\
\text { Only control }\end{array}$ & $\begin{array}{c}\text { (3) } \\
\text { Deliberate } \\
\text { Participation } \\
\text { Only AC } \\
\end{array}$ \\
\hline Active choice & $\begin{array}{c}-0.0201 \\
(0.0387)\end{array}$ & & \\
\hline Recurrences & $\begin{array}{l}-0.0302 * \\
(0.0180)\end{array}$ & $\begin{array}{c}-0.0306^{*} \\
(0.0170)\end{array}$ & $\begin{array}{c}0.000745 \\
(0.0182)\end{array}$ \\
\hline Recurrences X Active Choice & $\begin{array}{c}0.0327 \\
(0.0253)\end{array}$ & & \\
\hline Controls & Yes & Yes & Yes \\
\hline Observations & 1,575 & 802 & 773 \\
\hline
\end{tabular}

Could the observed effects mainly be driven by passengers that simply fail to notice the offsetting option in the booking process? First, this seems unlikely as the offsetting program has been highlighted prominently in the booking system (see screenshot in Table A1).

Second, even if passengers had indeed overseen the option in the first booking decision, it would be less likely to happen in subsequent booking decisions in the AC group as they were prompted to make a decision during the first booking. Hence, after their first booking, all subjects should have been made aware of the offsetting option. If only unawareness was the driver of the effect in the first booking, the prompt should be ineffective (or at least much less effective) in the second booking. We observe, however, that the effect of the prompt remains rather stable when comparing the first and second bookings. Again, a substantial share of passengers chooses to offset only when prompted to decide. (Figure 1). This observation provides first insights that a significant proportion of passengers continuously tries to avoid taking an offsetting decision in AC.

Analyzing individual behavior in repeated booking decisions supports this argument even more. Table 5 reports a transition matrix for returning customers, comparing their behavior between the first and the second booking. A crucial insight is that individuals in general tend to stick to their previous decision (see diagonal entries). Of the deliberate compensators, $76.3 \%$ again confirm their choice in the second booking decision. Similarly, $73.1 \%$ of the 
deliberate non-participants again actively decline to take part in the program in the second booking.

Behavior is less stable for those who were prompted to decide, but we observe substantial stability here as well. Nearly half of the prompted participants (49.2\%) and prompted nonparticipants (44.8\%) show the same patterns in the second booking. This provides further evidence that the individuals consciously avoid decision taking. If behavior in the first booking decision was mainly due to unawareness of the offsetting option, prompted travelers should not behave differently from their deliberate counterparts in subsequent decisions. However, prompted offsetters and deliberate offsetters again differ in terms of deliberate participation when booking for the second time (25.4\% vs. 76.3\%, $\mathrm{p}<0.001$, Chi ${ }^{2}$-test). Instead, a much larger share of the prompted participants again waits for the prompt to decide before choosing to participate $\left(49.2 \%\right.$ vs. $3.2 \%, \mathrm{p}<0.001, \mathrm{Chi}^{2}$-test). Similar differences are observed for prompted vs. deliberate non-participants.

Most notably, the switch of prompted to deliberate choices is not symmetric for participants and non-participants. $25.4 \%$ of the prompted compensators deliberately take part in the program when returning to the website for the next time (Table 5 and Figure A2). ${ }^{7}$ This picture looks different for those passengers who chose not to participate when prompted during their first booking. We observe that $49.6 \%$ of these individuals now deliberately decline to offset their emissions. The difference between the two groups is significant (25.4\% vs. $49.6 \%, \mathrm{p}<0.001, \mathrm{Chi}^{2}$-test). One potential explanation for this observation is that saying "No" in the presence of the highlighted active choice request may be perceived as even less pleasant than saying "No" in the more neutral screen prior to the prompt. This explanation adds a new facet to the idea of strategic ask avoidance.

\footnotetext{
7 10.2\% of the prompted participants now act as deliberate non-participants. That is, in total 35.6\% of the prompted participants in the first booking decision make a choice without having to be reminded in the second booking decision. 64.5\% of the first booking "prompted participants" again see the request for taking action in the second booking. The majority of them (49.2\% of all first booking prompted participants) finally enter the offsetting program again as prompted participants in the second booking decision.
} 
Table 5: Subsequent decision behavior, transition matrix

\begin{tabular}{|c|c|c|c|c|c|}
\hline Dec 1 & No & $\begin{array}{c}\text { Undecided } \\
\rightarrow \text { No }\end{array}$ & $\begin{array}{c}\text { Undecided } \\
\rightarrow \text { Yes }\end{array}$ & Yes & Obs \\
\hline No & $\begin{array}{c}141 \\
(73.1 \%)\end{array}$ & $\begin{array}{c}45 \\
(23.3 \%)\end{array}$ & $\begin{array}{c}0 \\
(0.0 \%)\end{array}$ & $\begin{array}{c}7 \\
(3.6 \%)\end{array}$ & $\begin{array}{c}193 \\
(100 \%)\end{array}$ \\
\hline Undecided $\rightarrow$ No & $\begin{array}{c}124 \\
(49.6 \%)\end{array}$ & $\begin{array}{c}112 \\
(44.8 \%)\end{array}$ & $\begin{array}{c}6 \\
(2.4 \%)\end{array}$ & $\begin{array}{c}8 \\
(3.2 \%)\end{array}$ & $\begin{array}{c}250 \\
(100 \%)\end{array}$ \\
\hline Undecided $\rightarrow$ Yes & $\begin{array}{c}6 \\
(10.2 \%)\end{array}$ & $\begin{array}{c}9 \\
(15.3 \%)\end{array}$ & $\begin{array}{c}29 \\
(49.2 \%)\end{array}$ & $\begin{array}{c}15 \\
(25.4 \%)\end{array}$ & $\begin{array}{c}59 \\
(100 \%)\end{array}$ \\
\hline Yes & $\begin{array}{c}15 \\
(16.1 \%) \\
\end{array}$ & $\begin{array}{c}4 \\
(4.3 \%) \\
\end{array}$ & $\begin{array}{c}3 \\
(3.2 \%)\end{array}$ & $\begin{array}{c}71 \\
(76.3 \%)\end{array}$ & $\begin{array}{c}93 \\
(100 \%)\end{array}$ \\
\hline Obs & 286 & 170 & 38 & 101 & 595 \\
\hline
\end{tabular}

Finally, we address the potential concern that subjects may have only limited memory and, despite being reminded of the offsetting program in their first booking decision, are again unaware of this option when returning for their next booking. If this was true, the effect of the request to decide should be weaker for quick returners and should increase with the time between the two bookings. However, as depicted in Figure 2, the effect of the prompt seems to be stable. If at all, it is even higher if there is little time between the two decisions. ${ }^{8}$ Similarly, also the shares of deliberate participation speak against this hypothesis, as there is even a mild increase for larger time lags, and generally similar levels as in the control group. As the time between bookings does not affect behavior, we have no reason to believe in restored unawareness due to bad memory.

Figure 2: Participation rates in second booking depending on temporal distance between the first and the second booking decision

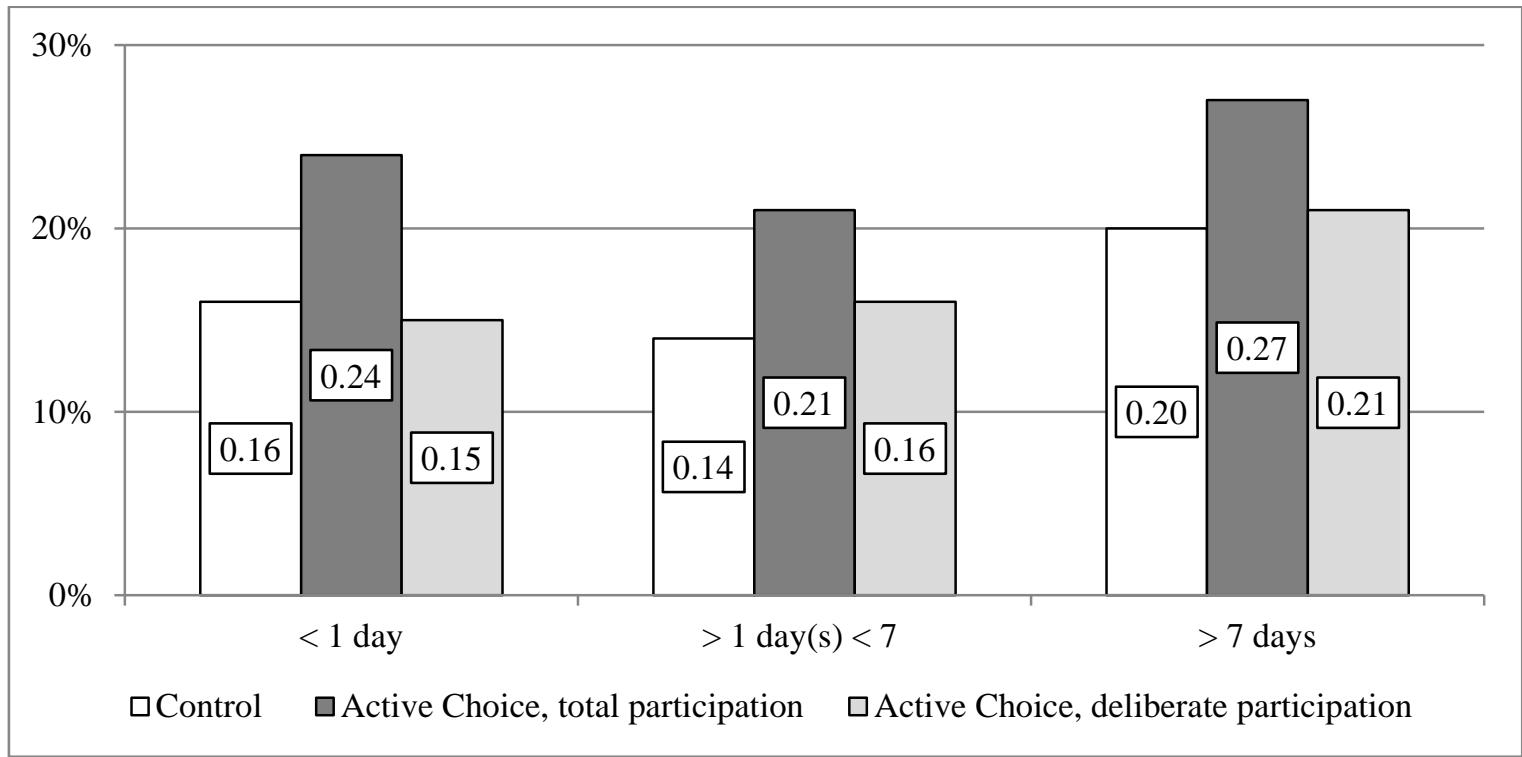

Note: Number of observations: Control: $n=97$ (<1 day: $n=33$; $>1$ day(s) $<7$ days: $n=39$; $>7$ days: $n=25)$, Active Choice: $n=139$ ( $<1$ day: $n=41$, delib. participation $n=26 ;>1$ day(s) $<7$ days: $n=58$, delib. participation $n=44 ;>7$ days: $n=40$, delib. participation $n=31$ )

\footnotetext{
${ }^{8}$ Similarly, also the share of all prompted subjects, i.e. both prompted participants and non-participants, does not increase with the temporal distance between bookings.
} 
In summary, we observe two major long-run effects of the design requiring an active choice: First, the share of deliberate participation remains higher in contrast to the control group. Second, requiring an active choice still effectively increases the share of carbon neutral trips with decreasing efficiency over time. A substantial share of prompted individuals again requires prompting in subsequent bookings. Comparing follow-up behavior of prompted participants and prompted non-participants as well as investigating subsequent behavior of deliberate and prompted participants provides suggestive evidence that subjects continuously try to avoid an explicit decision.

\subsection{Persistence of treatment effects}

Finally, we analyze whether the active choice treatment also affects behavior after treatment removal and leads to spillover effects. We observe returning customers in a subsequent experimental phase where treatment differences between the two groups were removed. In this follow-up phase, all subjects were asked to decide actively. In addition, some subjects received subsidies. In three rebate conditions, customers paid only $75 \%, 50 \%$, or $25 \%$ of the normal price to offset their emissions. In three corresponding matching conditions, the amount of carbon offset was increased by 33.3\%, 100\% and 300\% at no cost, resulting in similar relative prices as in the rebate conditions (see Kesternich et al., 2016). ${ }^{9}$

Using data from these subsequent decisions, we compare behavior conditional on whether individuals were previously assigned to the AC or the control condition. Figure 3 illustrates that the tendency observed in Figure 1 persists in the absence of subsidies. Being assigned to the AC condition in the first phase (AC-AC) leads to higher participation rates even though subjects now face the same environment when making their offsetting decision (31\% vs. 15\%, $\mathrm{p}=0.17$, Chi ${ }^{2}$-test, first booking decision in the subsequent phase). ${ }^{10}$ This spillover effect vanishes once customers face a new choice situation with additional monetary incentives. When adding (matching or rebate) subsidies, behavior is much more similar (25\% vs. 22\%, $\mathrm{p}=0.58, \mathrm{Chi}^{2}$-test).

While the additional incentives qualitatively increase participation of the former control group subject, there is even a drop in participation for those who had faced the active choice condition in previous bookings. Observed levels in the presence of financial subsidies are weakly (but insignificantly) lower than in AC-AC, both for AC-rebate (31\% vs. $28 \%$, $p=0.73$,

\footnotetext{
${ }^{9}$ Note that for our analysis in Kesternich et al. (2016) we excluded all IDs that took part in part 1 of the program.

${ }^{10}$ When including subsequent bookings in this phase, differences become slightly more significant (e.g. p=0.13 for this test). The results do not change substantially when using offsetting quantities instead of participation as dependent variable.
} 
Chi $^{2}$-test) and AC-Match (31\% vs. 22\%, p=0.36, Chi $^{2}$-test). While our experimental design cannot provide a full rationale for this behavior, exploring participation behavior under switching incentives in more detail reveals some interesting patterns even though the observations are based on a rather small sample size. Table A1 shows the participation of an individual in the first booking in phase 2 (with AC, rebate or matches) depending on the participation decision in the last booking in phase 1 in AC. Under AC-AC, nearly 83\% of the participants stick to their decision (participation or no participation) when moving to the second phase of the experiment. In AC-Rebate, $8 \%$ of the total participants additionally step into the program when learning about a rebate scheme for the first time while no one drops out. In contrast, in AC-Match, the share of participants decreases. While about $4 \%$ of total participants who had not compensated in phase 1 now additionally step into the program when seeing the match for the first time, $10.5 \%$ drops out of the program when being assigned to a match treatment. While the matching mechanism increases participation (to some extent) at the extensive margin, a larger share of participants drops out of the program. One might speculate that subjects react differently to the different forms of incentives. In particular, applying active choice requirements and matching schemes subsequently may lead to motivational crowding out. Based on the observed levels, adding a matching scheme to an active choice requirement may even be counterproductive.

Figure 3: Persistence of treatment effects

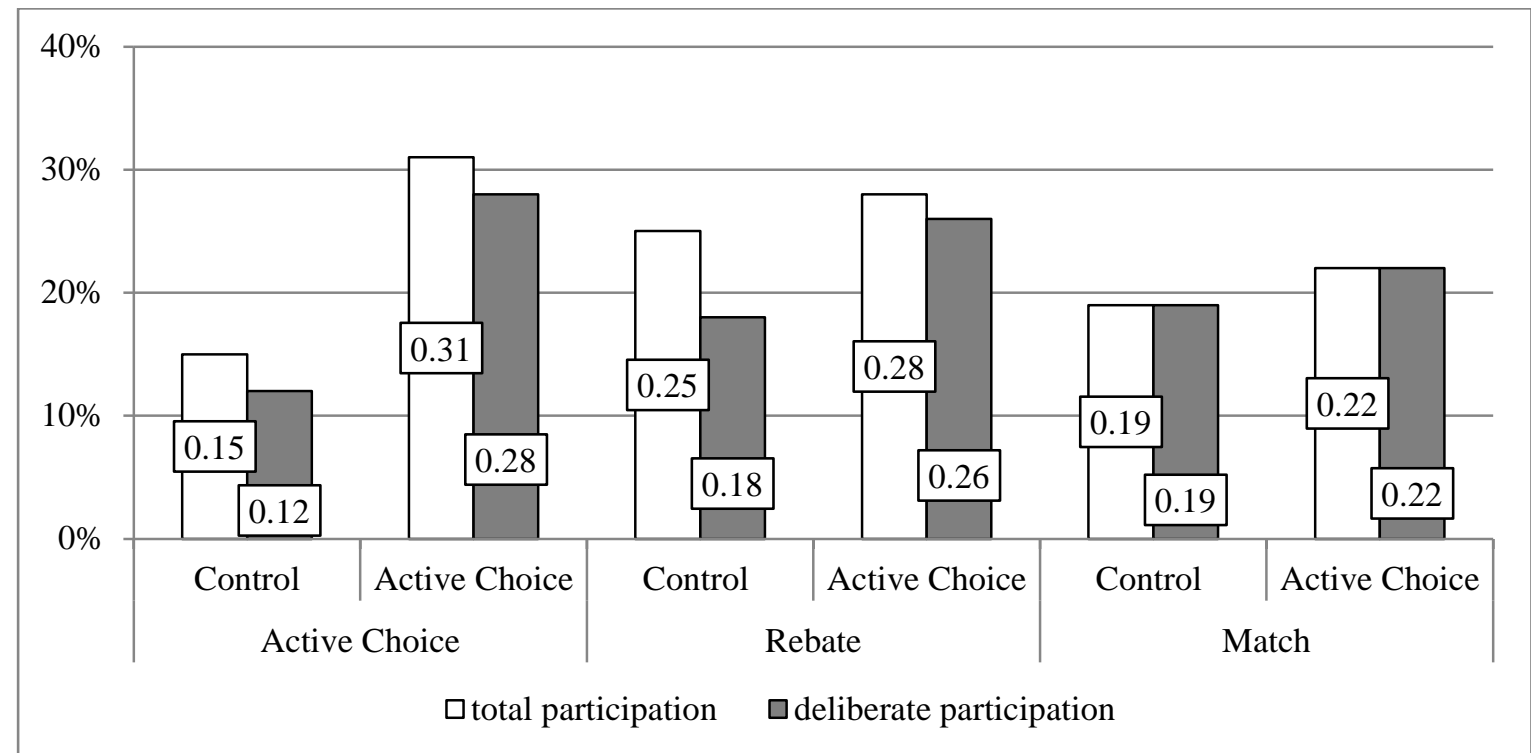

Note: The first row shows treatment assignment in the first phase (Control or Active Choice). The second row shows treatment assignment in the second phase (Active Choice, Rebate or Match). E.g., we find that the total share of participants in Active Choice in the second phase is higher (0.31) if subjects have been already assigned to Active Choice in the first phase compared to having been assigned to Control in the first phase (0.15). 


\section{Conclusion}

This paper analyzed the effect of being repeatedly asked for an active choice in a voluntary carbon offsetting program. In line with previous findings, our experimental results indicate that an "active choice" condition is able to increase the share of travelers who offset the carbon emissions from their long-distance bus travel by almost 50\% compared to a control condition where they could simply ignore the offsetting option. Most notably, we find similar treatment effects when analyzing repeated bookings, providing evidence that active choice requirements maintain increased contributions in the context of iterated decision making. The data from returning customers also provide insights into the underlying decision processes. We observe a substantial share of subjects not responding to the "ask", even if they were made aware of the offsetting option in a previous booking. This provides suggestive evidence that the effectiveness of the active choice condition is unlikely to be driven by inattention to the offsetting option, but rather by individuals continuously trying to avoid the decision.

The observed decision avoidance can be rationalized in different ways. To decide upon participation, subjects may try to evaluate how the offsetting program affects climate change. This might result in a complex analysis of different channels, considering questions of whether emissions from the bus travel have been correctly calculated, whether the offsetting program is effective, or whether individual action on climate change really makes a difference in the end. Hence, choice avoidance could simply result from individuals not wanting to engage in a complex decision as pointed out by Sunstein and Reisch (2013). As participation in the offsetting program results in voluntary contributions to a public good, an additional line of reasoning is worth considering. Altruistic persons may attempt to avoid being asked for voluntary contributions. Andreoni et al. (forthcoming) argue that there is a trade-off for altruists in such situations: either they give and feel good or they do not give and feel guilty. Sophisticated altruists, aware of these options, may try to avoid the "ask". Our study adds to the field experimental evidence provided by Andreoni et al. (forthcoming). They observe behavior in response to a public ask which may serves as a way to enforce decision-making and at the same time induces social pressure on the answer itself. Hence, it remains unclear which of the two channels dominates and, in particular, if the public nature of the "ask" is a prerequisite for the observed effect.

In our setting, we use a more anonymous enforcement mechanism of decision-making and find similar results. Hence, our findings suggest that even a computerized "ask" presented on a website, without any public exposure, can lead to similar avoidance behavior as being 
confronted with a personal "ask", with eye contact, as long as individuals are forced to take a decision. This points out a potentially neglected role of a public ask: it may simply force individuals to take a decision. In terms of self-image concerns, being non-responsive to a demand explicitly directed to oneself may come close to explicitly denying to give. In both cases, there is little room for excuses, like pretending to oneself not to have seen the "ask". As we found similar effects when introducing a mechanical enforcement of decision-making in the anonymous setting of online bookings, it seems likely that self-image concerns alone can provoke choice avoiders to change their behavior, even without any human interaction. Adena and Huck (2016) present evidence that points into a similar direction. In contrast to their findings, however, we do not observe a decline in subsequent participation. This could be due to the fact that the contribution levels were smaller in our case or because we studied contributions to a green good, which explicitly links public goods contributions to individual harm-related behavior. Future research could explore these channels and extend our analysis by systematically varying stakes, goods or by looking at even longer time series.

From a policy perspective, our results indicate that requiring an active choice can have strong effects. This form of intervention hence represents an interesting alternative to opt-out settings, which face legal challenges in many countries. Our results add to the debate on how to apply nudges, e.g. to promote environmental policy goals (List and Price 2016). In particular, we demonstrate that engaging people in an active decision on whether to offset their carbon emissions has a positive effect on participation not only in the short-term but also in the long-term. Individual dynamics revealed a significant degree of persistency in behavior, leading to behavioral spillover for decisions in sufficiently similar situations. Subjects in AC participate more often in subsequent unprompted decisions. On the other hand, subjects given the possibility to avoid the ask for some time continue to contribute less than subjects in the AC condition even when both groups are asked to make an active choice. These findings go beyond the measurement of immediate effects and suggest that the choice architecture might affect the formation of individual preferences. 


\section{Literature}

Adena M, Huck S (2016), Online fundraising, self-deception, and the long-term impact of ask avoidance, WZB Discussion Paper SP II 2016-306.

Andreoni J, Rao JM, Trachtman $\mathbf{H}$ (n.d.), Avoiding The Ask : A Field Experiment on Altruism, Empathy , and Charitable Giving, Journal of Political Economy.

Araña JE, León CJ (2012), Can Defaults Save the Climate? Evidence from a Field Experiment on Carbon Offsetting Programs, Environmental and Resource Economics 54, 613-626.

Bellman S, Johnson EJ, Lohse GL (2001), To Opt-In or Opt-Out? It Depends on the Question, Communications of the ACM 44, 25-27.

Beshears J, Choi JJ, Laibson D, Madrian BC (2008), The Importance of Default Options for Retirement Saving Outcomes: Evidence from the United States, in: Kay, S.J., Sinha, T. (Eds.), Lessons from Pension Reform in the Americas. Oxford University Press, pp. 59-87.

Cappers P, Fowlie M, Spurlock A, Todd A, Wolfram C, Baylis P (2015), Default Effects, Follow-on Behavior and Welfare in Residential Electricity Pricing Programs.

Carroll GD, Choi JJ, Laibson D, Madrian BC, Metrick A (2009), Optimal Defaults and Active Decisions, Quarterly Journal of Economics 124, 1639-1674.

Conte MN, Kotchen MJ (2010), Explaining the Price of Voluntary Carbon Offsets, Climate Change Economics 1, 93-111.

Dana J, Weber RA, Kuang JX (2007), Exploiting moral wiggle room: experiments demonstrating an illusory preference for fairness, Economic Theory 33, 67-80.

DellaVigna S, List JA, Malmendier U (2012), Testing for altruism and social pressure in charitable giving, The Quarterly Journal of Economics 127, 1-56.

Dinner I, Johnson EJ, Goldstein D, Liu K (2011), Partitioning Default Effects: Why People Choose Not to Choose, Journal of Experimental Psychology: Applied 17, 332-41.

European Court of Justice (2012), Judgement of the Court, Case C-112/11.

IINAS (Internationales Institut für Nachhaltigkeitsanalysen und -strategien) (2013), Globales Emissions-Modell integrierter Systeme, http://www.iinas.org/gemis-de.html, access on January 10, 2014.

Johnson EJ, Goldstein D (2003), Do Defaults Save Lives ?, Science 302, 1338-1339.

Kesternich M, Löschel A, Römer D (2016), The long-term impact of matching and rebate subsidies when public goods are impure: Field experimental evidence from the carbon offsetting market, Journal of Public Economics 137, 70-78.

List JA, Price MK (2016), Using Field Experiments in Environmental and Resource Economics, Review of Environmental Economics and Policy 10, 206-225.

List JA, Shaikh AA, Xu Y (2016), Multiple hypothesis testing in experimental economics, NBER Working Paper Series No. 21875.

Löfgren Å, Martinsson P, Hennlock M, Sterner T (2012), Are experienced people affected by a pre-set default option - Results from a field experiment, Journal of Environmental Economics and Management 63, 66-72.

McKenzie CRM, Liersch MJ, Finkelstein SR (2006), Recommendations Implicit in Policy Defaults, Psychological Science 17, 414-420. 
Pichert D, Katsikopoulos K V (2008), Green defaults : Information presentation and proenvironmental behaviour, Journal of Environmental Psychology 28, 63-73.

Smith N., Goldstein D, Johnson EJ (2013), Choice Without Awareness: Ethical and Policy Implications of Defaults, Journal of Public Policy and Marketing 32, 159-172.

Sunstein C, Reisch L (2013), Green by default, Kyklos 66, 398-402.

Sunstein CR (2014), Choosing not to choose, Duke Law Journal 64.

Thaler RH, Sunstein CR (2008), Nudge: Improving decisions about health, wealth, and happiness. Yale University Press, New Haven, USA.

Trachtman H, Steinkruger A, Wood M, Wooster A, Andreoni J, Murphy JJ, Rao JM (2015), Fair weather avoidance: unpacking the costs and benefits of "Avoiding the Ask," Journal of the Economic Science Association 1, 8-14. 


\section{Annex}

Figure A1: Translated screenshots of control (left side) and Active choice treatment (right side)

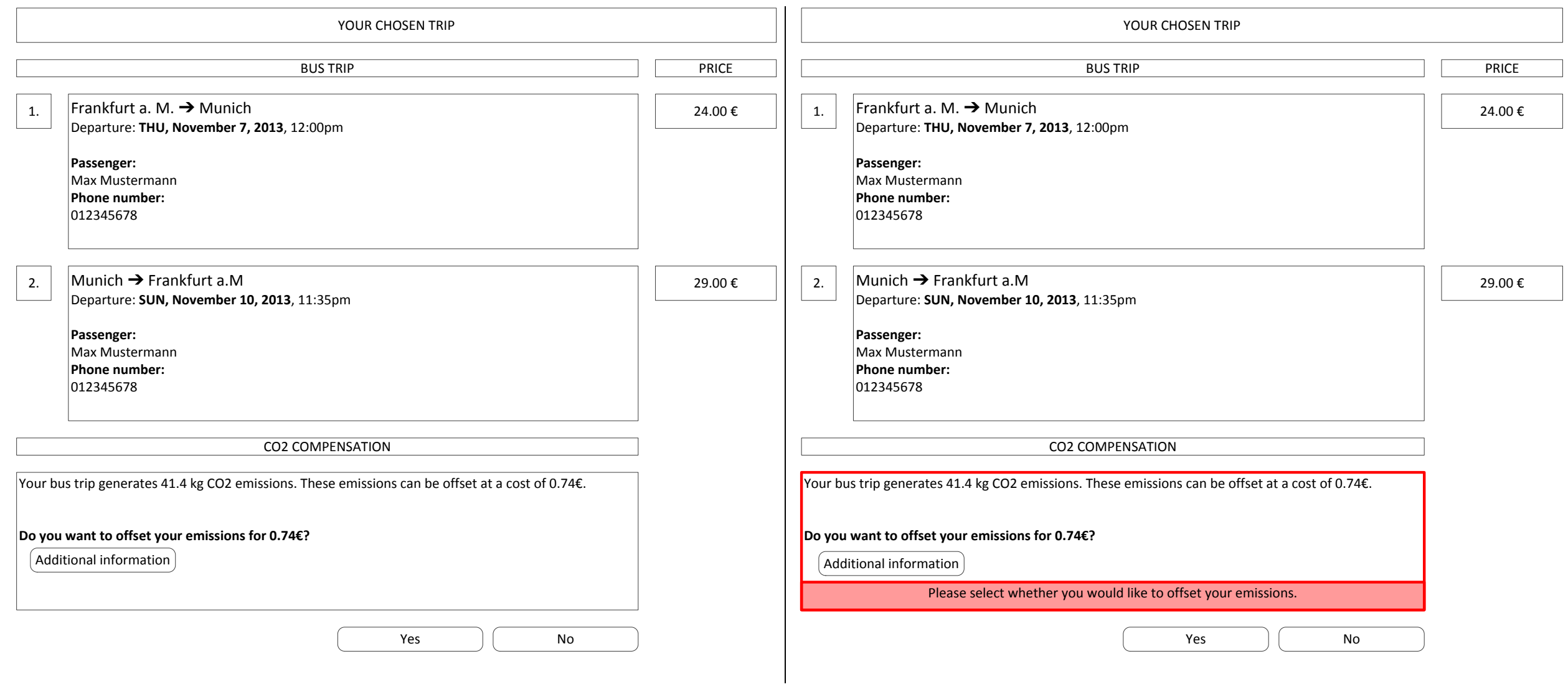


Figure A2: Subsequent decision behavior of prompted (non-) participants

Non-deliberate participants

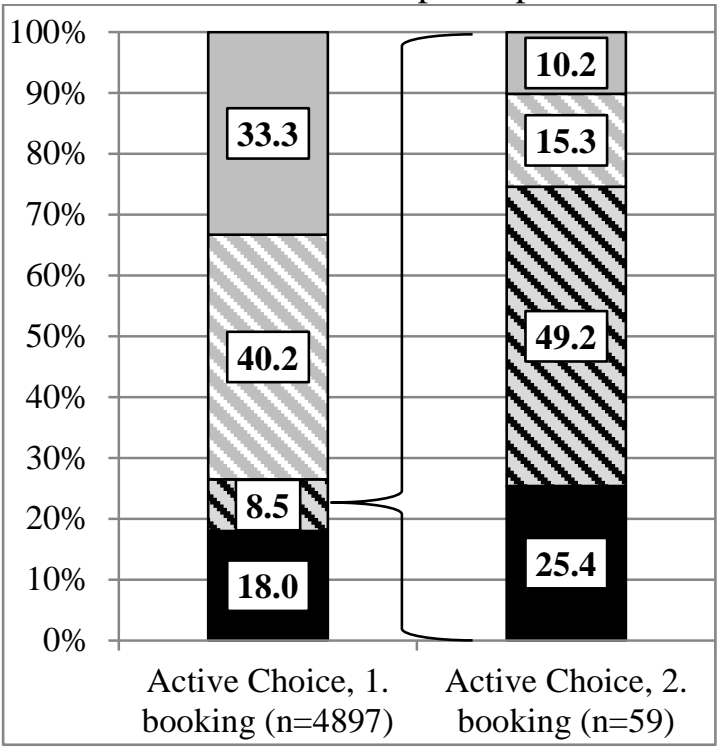

Non-deliberate non-participants

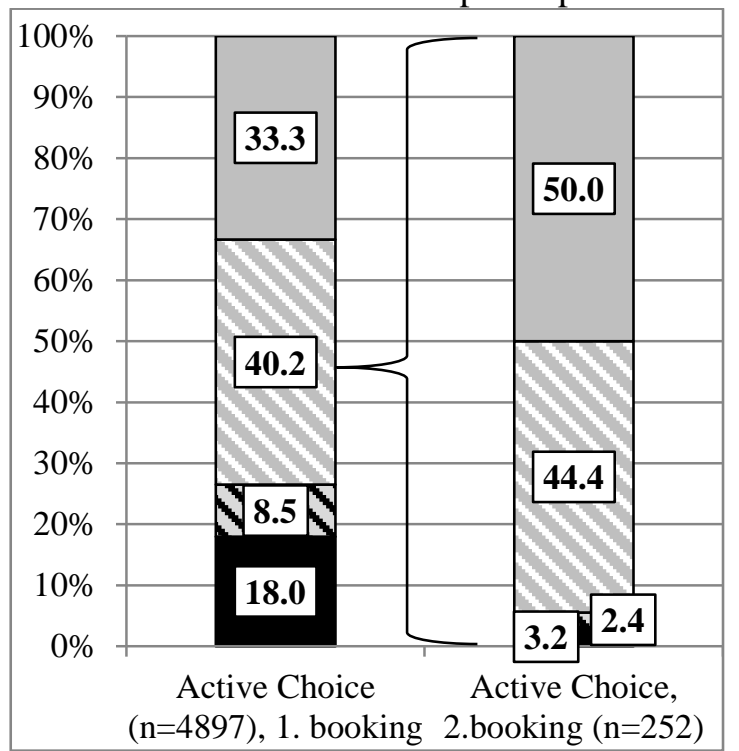

- deliberate participation $\mathbf{\nabla}$ prompted participation $\square$ prompted non-participation $\square$ deliberate non-participation $\square$ non participation

\section{Table A1: Changing incentives and participation}

\begin{tabular}{|c|c|c|c|c|c|c|c|c|c|c|c|}
\hline & \multicolumn{3}{|c|}{ AC (Phase 2) } & \multicolumn{3}{|c|}{ Rebate (Phase 2) } & \multicolumn{3}{|c|}{ Match (Phase 2) } \\
\hline & & & \multicolumn{2}{|c|}{ Compensated } & \multirow[b]{2}{*}{ TOTAL } & \multicolumn{2}{|c|}{ Compensated } & \multirow[b]{2}{*}{ TOTAL } & \multicolumn{2}{|c|}{ Compensated } & \multirow[b]{2}{*}{ TOTAL } \\
\hline & & & no & yes & & No & yes & & no & yes & \\
\hline \multirow{3}{*}{ 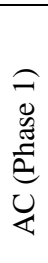 } & 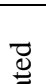 & no & $\begin{array}{l}N=17 \\
(58.6 \%)\end{array}$ & $\begin{array}{l}N=2 \\
(6.9 \%)\end{array}$ & $N=19$ & $\begin{array}{l}N=55 \\
(72.4 \%)\end{array}$ & $\begin{array}{l}N=6 \\
(7.9 \%)\end{array}$ & $N=61$ & $\begin{array}{l}N=51 \\
(67.1 \%)\end{array}$ & $\begin{array}{l}N=3 \\
(3.9 \%)\end{array}$ & $N=54$ \\
\hline & $\begin{array}{l}\text { ¿ే. } \\
\text { : }\end{array}$ & yes & $\begin{array}{l}N=3 \\
(10.3 \%)\end{array}$ & $\begin{array}{l}N=7 \\
(24.1 \%)\end{array}$ & $N=10$ & $\begin{array}{l}N=0 \\
(0 \%)\end{array}$ & $\begin{array}{l}=15 \\
(19.7 \%)\end{array}$ & $N=15$ & $\begin{array}{l}N=8 \\
(10.5 \%)\end{array}$ & $\begin{array}{l}=14 \\
(18.4 \%)\end{array}$ & $N=22$ \\
\hline & & TOTAL & $N=20$ & $N=9$ & $N=29$ & $N=55$ & $N=21$ & $N=76$ & $N=59$ & $N=17$ & $N=76$ \\
\hline
\end{tabular}

Note: This table shows compensation behavior in the first booking decision in phase 2 (with AC, rebate or matching) depending on the decision behavior during the last booking in phase 1 in AC. E.g., in total 29 participants of phase 1 also participated in phase 2. In both phases, they faced a AC design. Out of these 29 observations, 17 individuals (58.6\% of 29) did not compensate in both bookings, 7 (24.1\%) individuals compensated in one of the two booking decisions. 2 (3) individuals did not compensate in phase 1 (2) but compensated in phase 2 (1).

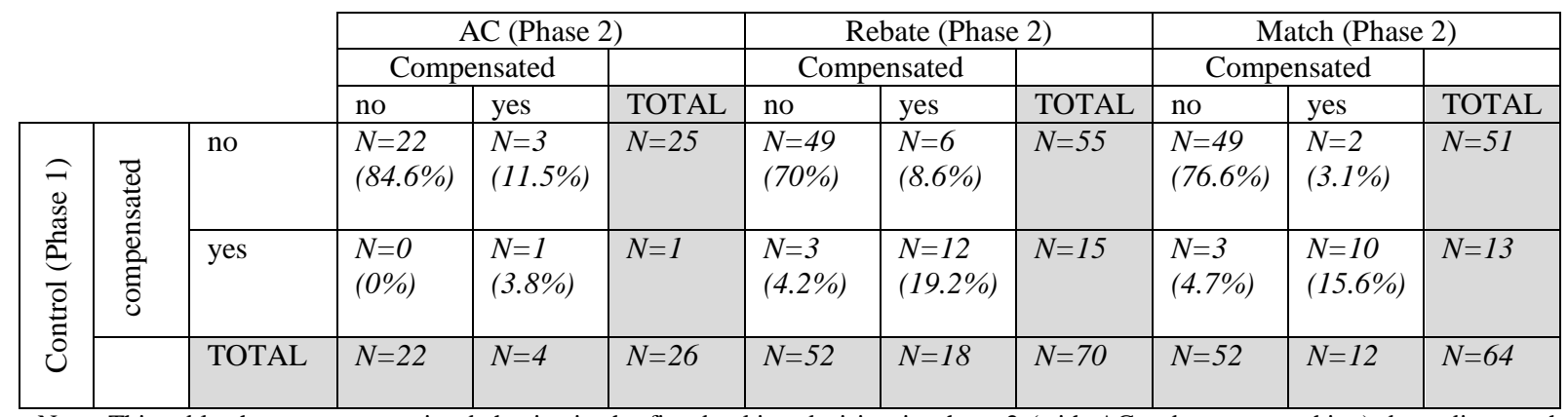

Note: This table shows compensation behavior in the first booking decision in phase 2 (with AC, rebate or matching) depending on the decision behavior during the last booking in phase 1 in control. E.g., in total 26 participants of phase 1 also participated in phase 2 . In phase 1, the faced a control design (Opt-in) and in phase 2 they faced a AC design. Out of these 26 observations, 22 individuals (84.6\% of 25) did not compensate in both bookings, 1 individual compensated in both booking decisions. 0 (3) individual(s) did not compensate in phase 1 (2) but compensated in phase 2 (1). 